\title{
ANALISIS KEMAMPUAN PEMECAHAN MASALAH MATEMATIK MATERI LINGKARAN SISWA SMP BERDASARKAN GENDER
}

\author{
Maranata Sanglimbo Buranda ${ }^{1}$, Martin Bernard ${ }^{2}$ \\ ${ }^{1,2}$ Pendidikan Matematika IKIP Siliwangi Bandung, Jalan Terusan Jendral Sudirman Cimahi \\ ${ }^{1}$ nataburanda@gmail.com, ${ }^{2}$ pamartin23rnard@gmail.com
}

\begin{abstract}
The purpose of this study was to analyze the problem solving skills of junior high school students based on student gender. This research is descriptive qualitative. Data from the research results obtained from the results of writing written questions and the results of oral interviews of 14 students of class VIII from Waringin Middle School, Bandung. The instrument used is 3 numbers of material questions that are in accordance with indicators of cognitive aspects. The results of this study indicate that from the problem description given and from the results of interviews about problem solving abilities of junior high school students with female gender on average, it is better than the problem solving ability on average junior high school students have a way to solve while solving problems. So that researchers can conduct research using active student learning methods to get better results, and also be able to understand other factors related to problem solving problems of junior high school students, both male and female students.
\end{abstract}

Keywords: Analysis, problem solving, circles

\begin{abstract}
Abstrak
Tujuan penelitian ini adalah untuk menganalisis kemampuan pemecahan masalah siswa SMP berdasarkan gender siswa. Penelitian ini bersifat deskriptif kualitatif. Data hasil penelitian diperoleh dari hasil pengerjaan soal tertulis dan hasil wawancara lisan dari 14 siswa kelas VIII dari SMP Waringin, Bandung. Instrumen yang digunakan adalah 3 nomor soal materi lingkaran yang sesuai dengan indikator aspek kognitif kemampuan pemecahan masalah. Hasil dari penelitian ini menunjukkan dari soal uraian yang diberikan dan dari hasil wawancara disimpulkan bahwa kemampuan pemecahan masalah siswa SMP yang bergender perempuan rata-rata adalah lebih baik daripada kemampuan pemecahan masalah pada rata-rata siswa SMP bergender laki-laki tampak dilihat dari cara berpikir dan cara memahami serta menyelesaikan soal. Peneliti menyarankan agar dilakukan penelitian lanjut dengan menggunakan metode pembelajaran siswa aktif untuk mendapatkan hasil yang lebih baik, dan juga agar dapat diketahui faktor lain yang mempengaruhi kemampuan pemecahan masalah siswa SMP, baik pada siswa laki-laki maupun siswa perempuan.
\end{abstract}

Kata Kunci: Analisis, pemecahan masalah, lingkaran

Cara Mengutip: Buranda, S.M., Bernard, M., (2018). Analisis Kemampuan Pemecahan Masalah Matematik Materi Lingkaran Siswa Smp Berdasarkan Gender. JPMI - Jurnal Pembelajaran Matematika Inovatif, 2 (1), 33-40.

\section{PENDAHULUAN}

Bagi para siswa-siswi Sekolah Menengah Pertama secara umum masih menganggap pelajaran matematika adalah salah satu pelajaran yang paling tidak disenangi karena bagi mereka 
matematika itu sangat susah dan tidak menarik(Timutius, 2018). Padahal matematika sangat penting karena tidak terlepas kaitan dengan kehidupan sehari-hari (Chotimah, 2018), sedangkan pencapaian prestasi siswa mengenai tentang matematika tidaklah mudah, dibutuhkan bukti dalam memecahkan masalah (Bernard, 2018), untuk mengatasi hal tersebut alternatif pendekatan yang digunakan adalah pendekatan pembelajaran berbasis masalah (Al Ayubi, 2018). Karena kemampuan pemecahan masalah merupakan inti dalam proses pembelajaran (Maharani, 2018) maka setiap siswa yang belajar matematika perlu menguasai dan memiliki kemampuan pemecahan masalah matematis. Hendriana, et al, 2017, mengatakan bahwa (1) Pemecahan masalah matematik merupakan kemampuan yang tercantum dalam kurikulum dan tujuan pembelajaran matematika (KTSP Matematika 2006, Kurikulum Matematika 2013, NCTM 1995); (2) Branca (Sumarmo 2006b, 2010) mengemukakan bahwa pemecahan masalah matematis merupakan tujuan utama pembelajaran matematika, bahkan jantungnya matematika. Selain itu pemecahan masalah merupakan satu kemampuan dasar dalam pembelajaran matematika; (3) Pemecahan masalah matematis membantu individu berfikir analitik; (4) Belajar pemecahan masalah matematis pada hakekatnya adalah belajar berpikir, bernalar, dan menerapkan pengetahuan yang telah dimiliki; (5) Pemecahan masalah matematis membantu berfikir kritis, kreatif, dan mengembangkan kemampuan matematis lainnya.

Hakekat dari pembelajaran tidak lain adalah adanya proses interaksi antara peserta didik dengan lingkungannya yang membuat perubahan perilaku ke arah yang lebih baik. Peran guru yang utama dalam proses belajar adalah membuat sedemikian rupa agar lingkungan dapat mendukung terjadinya perubahan perilaku yang lebih baik terhadap siswa didik. Dalam banyak hal para siswa sering kali membutuhkan bantuan dari luar diri mereka, karena seringnya mereka menghadapi kendala-kendala yang sulit diatasinya. DetikNews pernah melansir bahwa PISA-OECD tahun 2013 mengumumkan survey mereka bahwa dari 65 negara yang disurvey Indonesia menduduki peringkat 64 . Hasil survey itu berarti $90 \%$ siswa Indonesia memiliki kemampuan pemecahan masalah matematis yang buruk. Keadaan ini sangat memerlukan penanganan yang baik agar supaya segera ditemukan solusi bagi perbaikan kemampuan matematis siswa, khususnya kemampuan pemecahan masalah matematis siswa yang merupakan salah satu aspek kemampuan kognitif matematis siswa.

Menurut Polya (1973, Hendriana 2017), usaha yang dilakukan untuk mencari jalan keluar dari suatu masalah untuk mencapai tujuan yang hendak dicapai itu adalah suatu pemecahan masalah. Menurut Polya (1985, Hendriana 2017), ada 4 langkah dalam proses pemecahan masalah yaitu, (1) Mengidentifikasikan unsur-unsur yang diketahui, ditanyakan, dan kecukupan unsur yang diperlukan; (2) Merumuskan masalah matematis atau menyusun model matematisnya; (3) Memilih dan menerapkan strategi apa yang akan digunakan untuk menyelesaikan masalah; (3) Menjelaskan atau menginterpretasikan hasil penyelesaian masalah yang diperoleh

Tujuan penelitian ini adalah untuk menghasilkan suatu analisa tentang kemampuan pemecahan masalah matematis siswa SMP berdasarkan gender siswa, khususnya materi lingkaran, yang nantinya dapat didorong menjadi dasar dari penelitian lanjut untuk mendapatkan solusi dari rumusan masalah tersebut di atas.

\section{METODE}

Metode penelitian ini bersifat deskriptif kualitatif yang bertujuan untuk mendeskripsikan kemampuan pemecahan masalah siswa SMP, berdasarkan gender siswa, dalam memecahkan 
soal matematika materi lingkaran. Waktu penelitian pada semester genap tahun ajaran 2017/2018. Subjek penelitian adalah 14 siswa kelas VIII SMP Waringin, Kota Bandung. Keempat-belas siswa tersebut, yang terdiri dari 7 orang siswa dan 7 orang siswi, dipilih secara acak dari 4 kelas di sekolah tersebut. Teknik pengumpulan data melalui: 1) observasi; 2) tes soal pemecahan masalah matematik berbentuk uraian. Instrumen penelitian adalah 1 set soal yang berisi 3 nomor soal yang sesuai dengan indikator aspek kognitif pemecahan masalah tentang lingkaran. Data hasil pengamatan dipadukan dengan hasil tes yang berbentuk uraian. Kemudian data dianalisis dengan lebih fokus pada indikator kemampuan pemacahan masalah matematik siswa, yakni :

mengidentifikasi unsur diketahui dan ditanyakan, merumuskan masalah dan memilih strategi, serta menjelaskan hasil. Soal tes no 1 memuat indikator menjelaskan hasil penyelesaian masalah yang diperoleh, soal no 2 memuat indikator memilih dan menerapkan strategi yang akan digunakan, dan soal no 3 memuat indikator mengidentifikasikan unsur-unsur yang diketahui, ditanyakan, dan indikator merumuskan masalah matematis. Instrumen penelitian, yaitu 3 nomor soal yang dibuat oleh peneliti, sudah diujicobakan dengan mendapatkan nilai validitas sebagai berikut :

Tabel 1. Interpretasi Hasil Uji Coba Instrument Tes Kemampuan Pemecahan

\begin{tabular}{ccc} 
& Masalah Matematik Siswa SMP Materi Lingkaran \\
\hline Soal no & Koefisien korelasi Validitas & Kriteria Validitas \\
\hline 1 & 0,80 & Tinggi \\
2 & 0,59 & Sedang \\
3 & 0,50 & Sedang \\
\hline
\end{tabular}

\section{HASIL DAN PEMBAHASAN}

Hasil

Berikut temuan data kemampuan pemecahan masalah matematik siswa berdasarkan gender yang diperoleh dan pembahasannya :

Tabel 2. Temuan Data Hasil Penelitian Hasil Data Penelitian Jurnal Gender SMP Waringin

\begin{tabular}{|c|c|c|c|c|c|c|}
\hline \multirow{2}{*}{$\begin{array}{l}\text { Kode } \\
\text { Siswa }\end{array}$} & \multirow{2}{*}{ Gender } & \multicolumn{3}{|c|}{ Score soal } & \multirow{2}{*}{ Total score } & \multirow{2}{*}{ SM } \\
\hline & & 1 & 2 & 3 & & \\
\hline 01 & $\mathrm{~L}$ & 6 & 9 & 8 & 23 & 30 \\
\hline 02 & $\mathrm{~L}$ & 6 & 7 & 8 & 21 & 30 \\
\hline 03 & $\mathrm{~L}$ & 6 & 4 & 8 & 18 & 30 \\
\hline 04 & $\mathrm{~L}$ & 6 & 3 & 7 & 16 & 30 \\
\hline 05 & $\mathrm{~L}$ & 4 & 4 & 8 & 16 & 30 \\
\hline 06 & $\mathrm{~L}$ & 0 & 4 & 8 & 12 & 30 \\
\hline 07 & $\mathrm{~L}$ & 0 & 4 & 8 & 12 & 30 \\
\hline 01 & $\mathrm{P}$ & 9 & 9 & 9 & 27 & 30 \\
\hline 02 & $P$ & 9 & 9 & 9 & 27 & 30 \\
\hline 03 & $P$ & 5 & 9 & 6 & 20 & 30 \\
\hline 04 & $\mathrm{P}$ & 7 & 6 & 9 & 22 & 30 \\
\hline 05 & $\mathrm{P}$ & 7 & 7 & 7 & 21 & 30 \\
\hline 06 & $\mathrm{P}$ & 6 & 6 & 8 & 20 & 30 \\
\hline 07 & $\mathrm{P}$ & 6 & 6 & 8 & 20 & 30 \\
\hline
\end{tabular}


Buranda, \& Bernard, Analisis Kemampuan Pemecahan Masalah Matematik...

Tabel 3. Nilai rata-rata yang diperoleh per indikator

\begin{tabular}{cccc}
\hline \multirow{2}{*}{ Indikator } & \multicolumn{2}{c}{ Skor Rata-rata } & \multirow{2}{*}{ Skor Ideal } \\
\cline { 2 - 3 } & Laki-laki & Perempuan & 10 \\
\hline $\begin{array}{c}\text { Mengidentifikasi unsur } \\
\text { dan merumuskan masalah }\end{array}$ & 7,86 & 8,00 & 10 \\
$\begin{array}{c}\text { Memilih dan menerapkan } \\
\text { strategi }\end{array}$ & 5,00 & 7,43 & 10 \\
$\begin{array}{c}\text { Menjelaskan atau } \\
\text { menginterpretasikan hasil }\end{array}$ & 4,00 & 7,00 & 10 \\
\hline
\end{tabular}

Dari data yang diperoleh tampak bahwa siswa bergender perempuan lebih baik pada setiap indikator aspek kognitif yang digunakan. Pada indikator mengidentifikasi unsur dan merumuskan masalah gender wanita lebih unggul dengan poin rata-rata 0,14 . Pada indikator kedua memilih dan menerapkan strategi yang digunakan, siswa perempuan juga mendapat nilai yang lebih tinggi 2,43 dibanding siswa laki-laki. Dan yang paling terlihat selisih nilai yang cukup besar adalah pada indikator menjelaskan hasil pemecahan masalah, dimana siswa perempuan unggul dengan nilai 3,00 dibandingkan dengan siswa laki-laki.

Nilai rata-rata per-indikator aspek kognitif pada tabel 3 bila diubah menjadi nilai dalam satuan persen, maka akan didapat hasil seperti pada tabel 4 di bawah ini.

Tabel 4. Nilai rata-rata yang diperoleh per indikator dalam satuan persen

\begin{tabular}{lccc}
\hline \multicolumn{1}{c}{ Indikator } & \multicolumn{2}{c}{ Skor Rata-rata ( \% ) } & \multirow{2}{*}{ Skor Ideal ( \% ) } \\
\cline { 2 - 3 } & Laki-laki & Perempuan & 100 \\
\hline $\begin{array}{l}\text { Mengidentifikasi unsur } \\
\text { dan merumuskan masalah }\end{array}$ & 78,6 & 80,0 & 100 \\
$\begin{array}{l}\text { Memilih dan menerapkan } \\
\text { strategi }\end{array}$ & 50,0 & 74,3 & 100 \\
$\begin{array}{l}\text { Menjelaskan atau } \\
\text { menginterpretasikan hasil }\end{array}$ & 4,00 & 70,0 & \\
\hline
\end{tabular}

Bila dibuatkan konversi nilai rata-rata dalam persen tersebut di atas menjadi 3 kategori kemampuan siswa, maka dapat kita susun seperti pada tabel 5 di bawah :

Tabel 5. Konversi nilai menjadi kategori kemampuan

\begin{tabular}{cc}
\hline Nilai $(\%)$ & Kategori kemampuan siswa \\
\hline $80,0 \leq$ nilai $\leq 100$ & T i n g g i \\
$60,0 \leq$ nilai $<80,0$ & S e d a $\mathrm{g}$ g \\
nilai $<60,0$ & R e n d a h \\
\hline
\end{tabular}

Dengan membandingkan hasil pada tabel 4 dengan konversi nilai pada tabel 5, maka didapatkan hasil seperti pada tabel 6 . 
Tabel 6. Kemampuan siswa berdasarkan gender terhadap indikator aspek kognitif pemecahan masalah matematik

\begin{tabular}{ccc}
\hline \multirow{2}{*}{ Indikator } & \multicolumn{2}{c}{ Kategori Kemampuan Siswa } \\
\cline { 2 - 3 } & Laki-laki & Perempuan \\
\hline $\begin{array}{c}\text { Mengidentifikasi unsur } \\
\text { dan merumuskan masalah } \\
\text { Memilih dan menerapkan } \\
\text { strategi }\end{array}$ & Sedang & Tinggi \\
$\begin{array}{c}\text { Menjelaskan atau } \\
\text { menginterpretasikan hasil }\end{array}$ & Rendah & Sedang \\
\hline
\end{tabular}

Gambar $1-5$ di bawah menunjukkan hasil jawaban 5 siswa laki-laki sebagai berikut :

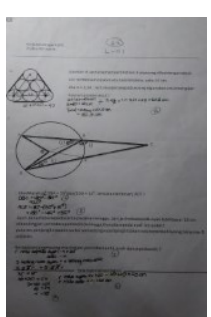

Gbr 1

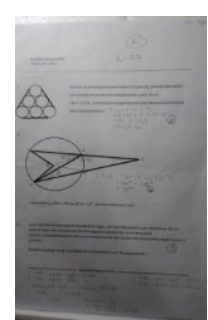

Gbr 2

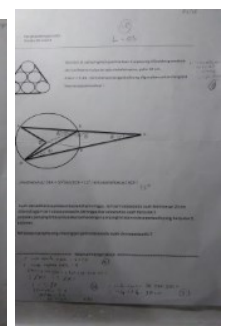

Gbr 3

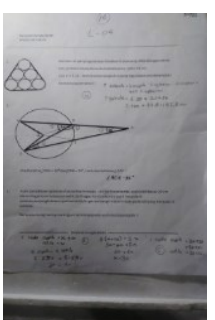

Gbr 4

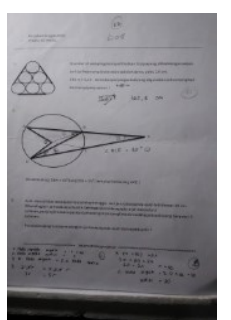

Gbr 5

Gambar 6 - 10 di bawah menunjukkan hasil jawaban 5 siswa wanita sebagai berikut :

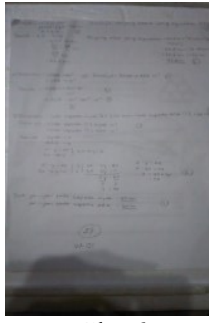

Gbr 6

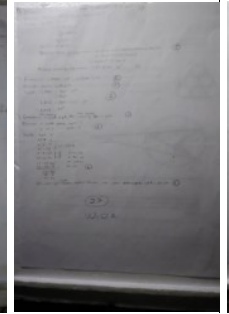

Gbr 7

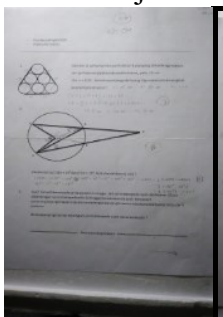

Gbr 8

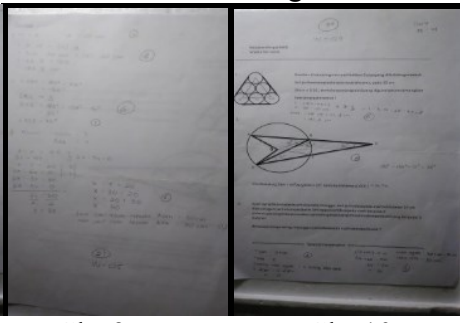

Gbr 9

Gbr 10

Terlihat jelas bahwa secara rata-rata siswa perempuan lebih unggul dalam aspek kognitif kemampuan pemecahan masalah matematik dibanding siswa laki-laki. Namun secara perorangan ada juga siswa laki-laki kemampuan pemecahan masalah matematiknya dapat mengungguli kemampuan pemecahan masalah matematik siswa perempuan, namun perbedaan cara berpikir laki-laki dan perempuan kecil hal sejalan dengan Firdausi (2019:40), kemampuan membaca dan memahami soal serta mengerjakan bahwa perempuan membuat langkah-langkah jawaban soal lebih bermakna dibandingkan siswa laki-laki, faktor ini juga sejalan dengan Shandy (2018:125). 


\section{KESIMPULAN}

Dalam hitungan rata-rata, aspek kognitif kemampuan pemecahan masalah pada siswa perempuan adalah lebih baik daripada siswa laki-laki, khususnya pada materi lingkaran.

Bahwa dalam masa pra remaja siswa laki-laki lebih aktif di sekolah, baik dalam kegiatan olah raga maupun dalam aktifitas pergaulan dalam lingkup sekolah, dibanding siswa perempuan turut mempengaruhi kemampuan berfikir mereka selain itu faktor cara berpikir laki-laki dan perempuan adalah kecil namun cara pemahaman dan cara mengerjakan soal siswa perempuan lebih memaknai soal dibandingkan siswa laki-laiki.

Perlu penelitian lanjut untuk mendapatkan hasil yang lebih akurat untuk mengetahui kemampuan pemecahan masalah pada siswa laki-laki dan perempuan

\section{UCAPAN TERIMA KASIH}

Tempatkan Ucapan Terimakasih, IKIP Siliwangi yang sudah mendukung penelitian baik sehingga dapat berjalan dengan baik.

\section{DAFTAR PUSTAKA}

Al Ayyubi, I. I., Nudin, E., \& Bernard, M. (2018). PENGARUH PEMBELAJARAN BERBASIS MASALAH TERHADAP KEMAMPUAN PEMECAHAN MASALAH MATEMATIS SISWA SMA. JPMI (Jurnal Pembelajaran Matematika Inovatif), 1(3), 355-360.

Bernard, M., \& Chotimah, S. (2018, September). Improve student mathematical reasoning ability with open-ended approach using VBA for powerpoint. In AIP Conference Proceedings (Vol. 2014, No. 1, p. 020013). AIP Publishing.

Chotimah, S., Bernard, M., \& Wulandari, S. M. (2018, January). Contextual approach using VBA learning media to improve students' mathematical displacement and disposition ability. InJournal of Physics: Conference Series (Vol. 948, No. 1, p. 012025). IOP Publishing.

FIRDAUSI WIDYA PUTRI, F. I. R. M. A. L. I. A. (2019). PROFIL KEMAMPUAN PENALARAN SISWA SMP DALAM MENYELESAIKAN MASALAH MATEMATIKA DITINJAU DARI TIPE KEPRIBADIAN DAN JENIS KELAMIN. MATHEdunesa,8(1).

Hendriana, H.H., et.al., 2017. Hard Skills dan Soft Skills Matematik Siswa. Bandung: Refika Aditama

Lestari, K.E., et.al., 2015. Penelitian Pendidikan Matematika. Bandung: Refika Aditama

Pisani, E. 2014. https://news.detik.com/berita/d-2491125/ri-terendah-si-pisa-wna-indonesiakids-dont- know-how-stupid-they-are? [28 Novemver 2017]

Farida, N., 2015.Analisis Kesalahan Siswa SMP Kelas VIII Dalam Menyelesaikan Masalah Soal Cerita

Matematika. Aksioma: Jurnal Pendidikan Matematika FKIP Univ Muhammadiyah Metro ISSN 2442-5419 Vol. 4, No.2 (2015) 42-52

Maharani, S., \& Bernard, M. (2018). Analisis Hubungan Resiliensi Matematik Terhadap Kemampuan Pemecahan Masalah Siswa Pada Materi Lingkaran. JPMI (Jurnal Pembelajaran Matematika Inovatif), 1(5), 819-826. 
Sandhi, D. P. A., Karimizzah, D. A., Monitasari, D., \& Suhartono, S. (2019, January). THE INFLUENCE OF SEX TOWARD THE COMPREHENSION READING ABILITY OF CLASS V STUDENTS IN THE ELEMENTARY SCHOOL OF PANJER VILLAGE. In Social, Humanities, and Educational Studies (SHEs): Conference Series (Vol. 1, No. 2, pp. 123-129).

Suciyati, Wahidin, Perbowo K.S.,2017.Analisis Kemampuan Berfikir Kreatif Matematis Siswa Ditinjau Dari Segi Gender. Prosiding Seminar Nasional Matematika dan Pendidikan Matematika STKIP Siliwangi Vol. 5, Tahun 2017. ISSN 2338-8315

Timutius, F., Apriliani, N. R., \& Bernard, M. (2018). ANALISIS KESALAHAN SISWA KELAS IX-G DI SMP NEGERI 3 CIMAHI DALAM MENYELESAIKAN SOAL PEMECAHAN MASALAH MATEMATIK PADA MATERI LINGKARAN $\mid$.JPMI (Jurnal Pembelajaran Matematika Inovatif), 1(3), 305-312. 
